\title{
A Model for Academic Planning
}

\author{
LARRY R. JONES*
}

\begin{abstract}
Under conditions of limited and selective growth, institutions propose resource allocation changes which are not strictly related to overall institutional enrollment levels. These proposals often focus attention on the resource impact of internal shifts in student demand and the desirability of maintaining minimum or "critical mass"levels of academic program breadth and quality. This paper addresses the academic planning procedures needed to advance non-enrollment driven resource maintenance and acquisition proposals at institutional and state levels.

The purpose of critical mass modeling for academic planning is to facilitate analysis, prioritization and negotiation of academic program alternatives and resources. The critical mass approach to academic planning would establish a campus-wide process and information base for prioritization of academic program development through (a) analysis of existing breadth and depth of faculty expertise in instruction and research at the subdisciplinary level, (b) identification of subdisciplinary areas in which academic units would like to provide instruction and research in the future. Critical mass denotes the level of course offerings and research which academic units could not reduce and still maintain programs which fulfill their own objectives compatible with the overall mission of their institution. Critical mass program size and "core" resource requirements would be established by academic unit faculty and then would be negotiated with committees of academic senates and with institutional administrations. The planning process described is designed for application in medium and large sized institutions in which formal, comprehensive and integrated academic/resource planning systems do not operate presently.
\end{abstract}

\section{RÉSUMÉ}

Un modèle en vue de la planification academique

Dans une conjoncture de croissance limitée et sélective, les institutions projètent, dans l'allocation des ressources, des modifications qui ne se rapportent pas nécessairement aux niveaux globaux des effectifs de l'institution. Ces propositions répondent souvent à l'impact sur les ressources des changements internes des demandes de la part des étudiants

*Assistant Professor, Policy Analysis Division, Faculty of Commerce and Business Administration, The University of British Columbia. 
et au caractère désirable de maintenir des niveaux minimums ou de "masse critique" dans la gamme et dans la qualité du programme académique. Cette étude s'adresse aux procédures de planification académique qui sont nécessitées pour permettre le maintien des ressources provenant des sources autres que les effectifs inscrits ainsi que des propositions pour des acquisitions provenant des institutions ou de l'état.

L'objectif de modèles basés sur la "masse critique" en vue de la planification académique est de faciliter l'analyse, la sélection des priorités et la négociation des alternatives au programme académique et aux ressources. L'approche de la "masse critique" à la planification académique verrait la mise sur pied d'une base de renseignements et d'un processus touchant la cité universitaire entière en vue de la sélection des priorités dans le développement des programmes académiques. Ceci comprendrait (a) une analyse de l'envergure et de la profondeur existantes des expertises du corps enseignant dans les domaines de l'enseignement et des recherches au niveau sous-disciplinaire, (b) l'identification des domaines sous-disciplinaires dans lesquels des unités académiques voudraient, à l'avenir, fournir des cours et entreprendre des recherches. La "masse critique" signifie le niveau des cours offerts et des recherches entreprises que le corps enseignant ne pourrait pas réduire tout en maintenant encore des programmes remplissant leurs propres objectifs compatibles avec la mission globale de leur institution. L'importance du programme de "masse critique" et les exigences centrales en termes de ressources seraient établies par les unités du corps enseignant et seraient, par la suite, négociées avec des comités choisis par des sénats académiques et avec des administrations institutionnelles. Le modèle du processus de planification décrit s'appliquerait aux grandes institutions ainsi qu'à celles de taille moyenne qui ne possèdent pas actuellement des systèmes de planification des ressources et du programme académique explicites, compréhensifs et intégrés.

\section{Introduction}

The topic of academic planning has probably never been so thoroughly discussed in the academic community as it has during the past five years, not even in the era of rapid growth in the 1960's. Accepting the condition of slow or no growth and under pressure from state governments, many colleges and universities are giving greater attention to internal program review and resource reallocation [4].

This paper explores methods of academic resource planning appropriate to the context of research oriented colleges and universities in late 1970's and 1980's.

For the purposes of this exploration, institutional academic planning can be defined as an interactive process in which institutional and academic unit goals, and the means for achieving goals', are negotiated between faculty, administrators, students and other parties within and outside the university. Academic planning includes coordination of tasks required to provide instruction, research and supporting service. Thus, academic planning integrates concepts and activities from academic program review, budgetary planning, and academic administration.

The purpose of the prescriptive critical mass planning model proposed here would be to (a) facilitate planning, negotiation and prioritization of academic program alternatives in the "steady state", and to (b) enable academic units and universities and colleges, 
especially public institutions, to justify resource acquisition and retention on a basis other than student enrollments. Critical mass program size and "core" resource requirements would be negotiated with committees of academic senates and with institutional administrators similar to the ways in which budgets and plans are now negotiated, except that proposals would be reviewed and resources would be allocated on the basis of better defined academic program and disciplinary characteristics than are available in many institutions presently. In addition these methods would operate within a well defined institutional planning process.

\section{Genesis of The Critical Mass Approach to Institutional Academic Planning}

The concept of critical mass, borrowed from physics and applied to academic planning and program analysis, is used here to denote the size and sufficiency of academic programs and resources at several different organizational levels. ${ }^{1}$ At campus or multi-campus levels, it can be applied to define the minimum and necessary program breadth required on a campus or within a multi-campus university to fulfill the educational mission and objectives of the campus and of the larger system, given agreement on institutional missions and objectives between campuses and central planners in multi-campus universities, and conformance with state-level higher education plans.

The genesis of the critical mass concept lies in the early development of academic programs in major research-oriented universities and colleges in the nineteenth and early part of the twentieth centuries. The notion that a discipline ought to have certain curricula, taught by faculty with research backgrounds in particular subdisciplinary areas, was common among the prominent faculty members around whom departments were formed. ${ }^{2}$ This tradition had been inherited to a considerable extent from European universities, especially from the "German model" established at the University of Berlin in the early 19 th century and implemented initially in the U.S. at Johns Hopkins and elsewhere [7] .

In a period ranging from the mid and late 1950's to the late 1960's, when enrollments were growing rapidly, it became evident to some institutional executives, budget staff and faculty involved in planning and resource allocation that academic unit use of quantitative proxies in program and budget change proposals, such as student/faculty ratios, numbers of courses taught, the ratio of courses taught to faculty were not sufficient for decision-making. ${ }^{3}$ This was especially evident for allocative decisions on faculty positions and academic support resources.

As proposals for development of new programs were reviewed, it became evident that attempting to plan for new programs on the basis of student/faculty ratios was inadequate, and that justifications for new programs and growth of existing programs had to center on unit specific faculty and curricular needs, augmented by actual and projected data on student demand and faculty workload policies. Evolution of the critical mass approach to planning and budgeting recognized tendencies in universities and colleges for (a) development of data on program costs which were often, due to their level of generalization, inadequate for academic program and subprogram resource allocation, and (b) incorporation of program cost data into formulae which came to be regarded as proper tools for resource allocation. It became obvious that many academic program resource allocation approaches treated departments and disciplines with unacceptable uniformity, as if one were shifting "the same eggs between different boxes". While acknowledging that in 
some cases faculty and curricula can be mobile between academic units, the critical mass approach recognizes that planning for academic units needs to be informed by actual information about faculty expertise and the breadth, depth and subdisciplinary organization of academic disciplines.

\section{Critical Mass Academic Planning Definition}

The approach to planning presented here is a programmatically based planning alternative to existing academic planning procedures for medium sized and large research-oriented universities and state universities and colleges. The central assumption upon which the postulated planning alternative rests is that academic planning should be based upon an exact understanding of existing instructional and research program plans, rather than methods which are limited in their predictive accuracy and do not provide a useful understanding of academic program breadth, e.g., student/faculty ratio approaches. The critical mass approach to planning is intended to indicate differences in the organization of faculty, curricula and research in different academic units on single campuses, and differences in organization of the same or similar disciplines between institutions. The critical mass approach assumes that curricula are designed and provided by academic units in response to student demand, but that student demand is not, nor should it be the most important factor in determining the subdisciplinary composition of academic unit instructional and research programs.

It is also assumed here that in a multi-campus university, academic planning should be based upon: (1) system-wide program differentiation, and delineation of functions of institutions within state systems of postsecondary education; (2) requirements that academic programs reflect distinct differences in campus educational missions; (3) the need to provide campus and system-wide decisions makers with a programmatic overview of actual campus disciplinary and instructional strengths and weaknesses as a guide for complimentary program differentiation, development and curtailment; (4) the necessity for accurate assessment of resource requirements resulting from increases or decreases in instructional demand for instructional programs; (5) the need to predict the effects on existing campus programs which result from the addition of students to other existing or new instructional programs (induced workload measures).

For purposes of explaining the critical mass academic planning mode, an academic unit is defined as an administrative entity composed of faculty members offering instruction in the titled subject matter of that unit. The term academic unit is used to permit generalization to account for differences in university and college academic organizational structures (departments, divisions, schools, colleges, etc.).

Instructional program is used in this context to describe the major and degree programs offered by universities through their departments, schools, colleges, inter-disciplinary and graduate groups, and other units constituted for the purpose of organizing curricula and providing instruction to students. The term research program is used to describe research activity conducted by faculty, assisted by students in some cases within and between academic units and within units especially designated for research (organized research units).

In reference to a discipline, groupings of similar curricula, instructional and research field concentrations are referred to as disciplinary areas. Independent of the organizational 
format in which teaching and research are performed, the level of organization below the discipline is specified as the sub-discipline, or the instructional or research field of specialization.

Critical mass in instruction at the academic unit level is defined as that portion of the curriculum which is essential to performance of both instructional and research missions, i.e., minimum curriculum and research which an academic unit could not reduce and still maintain a satisfactory academic program, given the mission of the institution and unit. Critical mass in research denotes the minimum breadth of research specializations which are necessary for an academic unit to support its critical mass instructional program, and that research which is deemed necessary independent of instruction. As stated earlier, determinations of the "satisfactoriness" of curricula and research breadth are made initially and principally by the faculty of an academic unit.

In order to clarify the procedure by which critical mass disciplinary and subdisciplinary fields would be defined, and to explain how these procedures fit into the overall mode of academic planning employed on a campus, a simplified step-by-step description of the critical mass data gathering, display and verification procedures is as follows:

(a) Academic units, including organized research units, develop goal statements within which they specify the subdisciplines they plan to initiate and terminate in the next five years. They would also identify the size of their curriculum in three states according to (i) minimum necessary coverage, (ii) future subdisciplinary areas and/or courses necessary to meet student demand, (iii) future areas and/or courses necessary to balance or "round out" academic unit curricula and course offerings (ideal state, unconstrained by institutional fiscal or faculty position projections/constraints). In drafting these statements, academic units could request staff assistance from academic planning and institutional research offices to aid in gathering data and drafting statements of objectives. The only uniformity which is necessary in drafting these statements is that one overall format be used, one which could be established by appropriate committees of the academic senate working with institutional academic executives and advised by selected "pilot" academic units, faculty advisory committee and institutional planning and research staff.

(b) Academic unit goal statements are reviewed by succeeding levels of the organizational hierarchy, the flow of this activity coordinated by the designated academic senate committee, campus academic executive and his staff in order to insure that some reasonable timetables for review are maintained.

(c) Once academic unit goal statements are finalized, institutional planning and research staff, working with academic unit faculty and non-faculty staff, assemble data profiles on each academic unit. These profiles are verified by academic units and become a part of an academic unit's goal statement or plan. These profiles include information on enrollments, instructional course load, faculty workload, and other performance indices which are displayed according to the subdisciplinary areas previously defined by academic units.

(d) The relationship between academic unit goals and performance by subdiscipline are examined by academic units, committees of the academic senate, and the campus academic executive staff in order to gain better understanding of how and why resources are being used as they are within and across units and disciplines.

(e) A committee or committees of the academic senate, assisted by the campus executive 
and his or her staff and advisory committees determine priorities for future allocation of faculty and support resources. Allocation plans require prioritization of preferences at this point, a task which involves considerable deliberation, consultation and negotiation. Decisions at this phase comprise the heart of the planning process, a fact which should not be understated. Planning for future allocations over a five year time span at this point is informed by the use of faculty renewal statistical modeling which predicts the number of academic appointments by level which will be available independent of injection of new positions or resources from outside the university. However, priorities thus established would be used to allocate new positions if they became available through state and/or multi-campus appropriations.

(f) Academic unit plans and priorities, and campus priorities are reviewed using the same process every third year on a routine basis to insure that academic unit plans are up-todate, and that campus-wide priorities are current.

(g) During the two to three year period in which plans and priorities are fixed, plans and critical mass data profiles are used in the ongoing budget and academic program review process, eliminating much of the need for duplicate and ad hoc data collection and refinement which usually accompanies these efforts. ${ }^{5}$

The intention here is not to imply that quantitative comparisons between academic units be used exclusively, nor that academic programs can be best understood through the use of quantitative proxies and data matricies. Indeed, the principal thrust of the procedure described here is to portray qualitatively the essential disciplinary coverage at both the academic unit and campus levels, as defined by the faculty themselves, in a way which justifies the allocation of resources necessary to maintain broad disciplinary coverage in a period of stabilized or declining student enrollments. The critical mass approach to planning maintains, in essence, that institutional faculty should teach curricula which they believe to be necessary in order to fulfill the missions of academic units and institutions, regardless of student demand. It is expected that quantitative data collected in critical mass modeling would be used in analysis of existing academic programs and new program initiatives.

Thus far, we have defined critical mass in reference to the academic activity of an institution, i.e., minimum curricular and research breadth. However, if we define planning as a process which includes implementation, it also is necessary to define methods for translating academic program planning into resource planning. Once critical mass disciplinary plans have been established, in order to guide resource allocation decision making it is necessary to define the levels of resources which are required to support critical mass instructional and research programs. Resources in this context are defined as people, time, money (fiscal resources), physical space, and other tangibles necessary for operation of an instructional program.

In order to make this translation, the concept of core resource requirements is utilized. The definition of core program resources fits into the critical mass program planning approach to differentiate between the minimum necessary coverage of curricula and research (critical mass), and the essential resource requirements (core) to sustain academic programs. Thus, academic staff required to teach a critical mass program may be defined as the core faculty. Core faculty may be identified according to their principal research and teaching subdisciplinary specializations as a means of translating program planning into faculty planning. Similarly, core teaching assistance support may be defined in relat- 
ion to the number of core courses requiring teaching assistants within the critical mass curriculum. Other core program resources, such as administrative support may be defined utilizing this methodology.

To translate academic program needs into resource needs, the critical mass/core planning approach would require comparison of information on academic unit instructional activity as a means of aiding faculty, campus planners and decision makers in understanding how academic units (a) view the status and development of their disciplines, and (b) currently utilize staff and support resources. Thus, in instructional planning, the critical mass curriculum, defined by disciplinary sub-specialization, and the core faculty of an academic unit can be related to academic program performance indices through the construction of quantitative matrices. Examples of these matrices are available from the author for readers who are interested in examining this procedure. For example, critical mass curricula by subdiscipline can be cross-referenced to the following variables, (a) course offerings, (b) student enrollments (further subdivided by student majors versus service load), (c) average class enrollment size, (d) frequency of course offerings, (e) predominant course type (lab, lecture, seminar), and (f) faculty teaching workload, e.g., courses or student credit units taught per term or per year.

The critical mass/core approach would permit evaluation of academic unit performance relative to qualitative performance statements rendered by academic units, a process facilitated by availability of more common indices of performance.

Although it is intended that the core concept be applied to define the minimum fiscal resources necessary to sustain critical mass academic program breadth, it is important to note the difference between critical mass as a budgetary strategy and critical mass as an academic planning methodology which attempts to inform decision makers about institutional academic activity. The emphasis here is on establishing the latter so that the former may be accomplished with greater effect at the multi-campus and/or state level.

The critical mass approach to planning is intended to enable the establishment of academic program priorities through (a) identification of existing program breadth and depth, and (b) comparison of the curricula of departments and disciplines, on a single campus and within a multi-campus university. The results of these comparisons are intended to enable university decision makers to plan more effectively for the establishment of different resource allocation standards for different types of programs, an approach which has been applied in allocation of budgets at the University of California, Berkeley and in modified form at other large public institutions. ${ }^{6}$

In advocating this approach to the development of an academic planning process, it is assumed that sound academic planning must rest upon clear statements of goals of individual academic units. Drafting academic unit goal statements is the initial step in defining the critical mass planning approach. Critical mass program size is generally to be determined by faculty negotiations within academic units. These statements should represent the actual thinking and strategies of deans, department chairpersons and faculty. Individual plans could perhaps best be drafted after careful review of department performance indices by instructional field of specialization. Data displayed by specialization may be useful for academic unit planning in that they reveal information about performance not previously known, or confirm and weight existing assumptions about the manner in which the units operate.

It may be argued that the critical mass planning approach is elitist in placing the 
responsibility for judgment of what ought to be taught jointly in the hands of campus faculty and non-faculty decision makers $[3,13]$. However, the use of techniques of performance measurement in instruction is intended to provide decision makers with information so that they can plan, to the limits of their knowledge, how to supply the highest quality instruction and most comprehensive curricula to students. It is intended that faculty, students and other members of the university community participate in the planning process consistent with the "open system" planning approach advocated by Michael and others who have researched this area $[8,1,2,9,12,14]$. The assumption here is that cost center control is and will continue to be exercised in universities and that faculty should participate more effectively in guiding these efforts. It is also assumed that it is better for this control to be exercised on campuses rather than by state higher education planners and budgeteers.

With respect to identification of research program critical mass, much of what this planning mode attempts to accomplish in defining critical mass for instruction rests upon existing and desired faculty research specializations. This is true simply because academic units in research-oriented universities tend to hire and promote faculty on the basis of research performance, and on the "fit" of the faculty members' areas of expertise into the curriculum either offered or planned by an academic unit. In short, the division of curricula into subdisciplinary areas of instructional specialization is guided to a great extent by the individual and collective research interests of the faculty.

For organized research unit planning, this integration is not so automatic. At present, it is difficult to discern the breadth, complimentarity or overlap of research activity accomplished in organized research units. Applying the critical mass concept to organized research unit activity would enable coordinative planning where little coordination now exists. Again, care must be taken to avoid the implication that application of critical mass techniques to research would result in guidance-oriented planning. This would be contrary to the arguments in favor of relatively unconstrained sponsored research in the university.

With this understanding, it is maintained here that identification of critical mass research programs would be useful to (a) relate organized research unit efforts to campus missions as articulated in academic plans and budgets, (b) identify the extent of integration of instructional specializations into current research efforts, (c) suggest areas of instruction not presently served by organized research units, (d) illuminate areas in which organized research efforts are weak or inappropriate. Relating subdisciplinary areas of research to instructional subdisciplinary fields and areas of faculty expertise would clarify criteria employed in the selection and promotion of faculty. It might also highlight the development of departmental strategies for reorganization of research in their disciplines.

As a start, research program breadth could be defined by identifying the sub-areas of a discipline in which research is actually engaged, information which could be gleaned from organized research unit annual reports and profiles. Areas of research which are vital to the maintenance and development of the field could also be established by intra-and inter-unit negotiation in the same manner employed for definition of instructional critical mass. This information could be obtained and the process coordinated by academic senate committees on research for example.

Utilizing these techniques, it would be possible to better coordinate organized research planning on and between campuses within a university or state system. Critical mass 
modeling of existing research efforts, because of its subdisciplinary concentration, would seem to be well suited to identification of essential similarities and differences in independent research efforts. An exact description of how this would be accomplished, beyond creation of a research program inventory supplemented by cross-indexing of faculty by areas of specialization will not be addressed further here.

Another topic which is not addressed here is how to set standards and criteria for evaluating academic planning models; e.g. clarity of strategy, operational feasibility, comprehensiveness of model, consistency with environmental constraints, etc. Some work has been done on academic planning evaluational criteria and this area certainly deserves additional attention $[5,6,9]$.

In conclusion, it is obvious that in the next decade, universities will need to plan so as to better utilize existing resources rather than to depend on the continuous injection of new resources. To do this, it appears likely that universities must know more about themselves than they do at present. This is not meant to imply that universities need to tell the outside world all that they learn about themselves. The critical mass approach to planning is based upon assumptions that planning should be process oriented and that the institutional learning which results from involvement in the planning process comprises at least half the reason for engaging in formalized planning. The other reasons are related simply to survival, and to the continued promotion of intellectual and personal vitality in our universities and colleges.

\section{FOOTNOTES}

1. The term critical mass is defined in physics as the mass of fissionable material required to produce a self-sustaining sequence of fission reactions in a system, or the minimum mass of fissionable material that will sustain a chain reaction. It is reputed that the term critical mass was first used in physics by Lise Meitner and Otto Frisch in 1939, explaining the nuclear chemistry experiments of Hahn and Strassmann conducted in Germany in 1938.

2. For examples, see Verne A. Stadtman, Centennial Record of the University of California [11].

3. The primary institutional example used for this study was the University of California, Berkeley and the University of California mult-campus system. The term critical mass was applied by Professor Raymond G. Bressler, Jr., Assistant Chancellor Errol W. Mauchlan, Institutional Research Director Sidney Suslow and other members of the faculty and administration involved in academic planning at Berkeley in the mid-1960's.

4. Observation made by Assistant Chancellor Errol W. Mauchlan, University of California, Berkeley, April 18, 1977.

5. Credit for specification of this sequence of planning events must be shared with G.A. Sasek, Principal Budget Analyst, University of California, San Diego [10].

6. For example, see The Budget for the University of California, Berkeley 1976-77, in which academic units were divided in categories relating their resource requirements to academic program development needs to indicate that different resource allocation standards should be applied to each category. Also, see The Trustees Budget for the California State University and Colleges 1977-78 which justified resources requested from the state to compensate for shifts in student demand to more resource in tensive modes and levels of instruction. Although this proposal was enrollment based, it argued that different resource justification/allocation standards should be employed for different disciplines relative to actual academic unit operating costs. 


\section{REFERENCES}

1. Bennis, W., Changing Organizations. New York: McGraw-Hill, 1966.

2. Benveniste, G., Bureaucracy. San Francisco: Boyd and Fraser, 1977.

3. Benveniste, G., "The Consequences of Excessive Educational Planning". Unpublished manuscript, University of California, Ber keley, 1978.

4. Bergquist, W. and W. Shoemaker, "Facilitating Comprehensive Institutional Development", A Comprehensive Approach to Institutional Development. Jossey-Bass, 1976.

5. Cope, R., "Qualitative Approaches to College and University Planning". Paper presented to the California Association for Institutional Research, February, 1978.

6. Dresch, S., "A Critique of Planning Models for Postsecondary Education". The Journal of Higher Education, 46, May/June 1975, pp. 245-286.

7. Kerr, C., The Uses of the University. Cambridge: Harvard University Press, 1963.

8. Michael, D., On Learning to Plan-And Planning to Learn. San Francisco: Jossey-Bass, 1973.

9. Patterson, F., "Institutional Planning in the Context of Change". Planning for Higher

Education, 6, August, 1977, pp. 1-8.

10. Sasek, G., "Status Report to the Campus Budget and Planning Task Force". Unpublished Report. University of California, San Diego, September, 1973.

11. Stadtman, V., Centennial Record of the University of California. Berkeley: University of California, 1967.

12. Thompson, J., Organizations in Action. New York: McGraw-Hill, 1967.

13. Trow, M., "The Public and Private Lives of Higher Education". Daedalus, 104, Winter, 1975, pp. 113-127.

14. Znaniecki, F., The Social Role of the Man of Knowledge. New York: Columbia University Press, 1940. 